\title{
Climate Resilient Indigenous Community Self-Help Practices in Oromo Gadaa System: The Cases of Sikkoo-Mandoo Oromo in Oromia, Ethiopia
}

\author{
Kassim Dedefo* Oli Wakayo Misbahu Aman \\ College of Agriculture and Environmental Science, Arsi University, Ethiopia
}

\begin{abstract}
Climate resilient livelihood is used to mitigate the adverse climatic effects. The farmers' livelihood vulnerable to extreme climatic events were recorded in study area. Hence, this study was aimed to investigate climate resilient indigenous livelihood practices in Oromo Gadaa system. Data were collected by 69 respondents' interview and literature review and analyzed by descriptive statistics. Indigenous early warning, conflict settlement, and community self-help were the climate resilient livelihood practiced in study area. Majority of farmers have been used indigenous early warning information forecasted by Raagaa Wogii. Tree ring, sediments layer, and wind direction have been used to know and predicts extreme climatic event in indigenous early warning system. In alleviating climatic effects of conflict, Gadaa system have allocated the responsibilities of every individual in indigenous conflict prevention and resolution. The Sadii walii dhoksuu, Sadii walii obsuu, Sadii walgorsuu and Araaraтии have been the conflicts prevention mechanisms settled by conflicting parties. The Ilmo-limmoo, Qora, and Gumaa have been conflict resolution techniques mainly settled by hayyuus, Ambaa Gadaa and Abbaa gadaas through hearing the causes in detail. Seera siiqqee has been used to settle the conflicts between man and woman whereas Guula has been the resolution mechanisms of political conflict. The community self-help practices: Ameesa dabarsu, Dabaree kenuu, Gegawo-gegesaa, Soruu, Hirphuu, Gumaata, Liqii, Qabdoo qabuuf, Qote-qotii, Sanyii kennuu, Woliif Tiksuu, Dhoofsisuu, Daboo, and Edir and/or Ekub have been indigenous climate resilient livelihood used in Gadaa system. Majorities of community self-helps have been the responsibilities of members in their clan, friends and families. So, the indigenous early warning system, conflict settlement and community self-help practices should legalized and used at a regional level. The evidences, reliability and effectiveness of the indigenous early warning system need further study.
\end{abstract}

Keywords: Climate resilient, Conflict settlement, Early warning, Spiritual leader

DOI: $10.7176 / \mathrm{JCSD} / 55-04$

Publication date: January $31^{\text {st }} 2020$

\section{INTRODUCTION}

\subsection{Backgrounds of the study}

Climate change is change in mean of climatic parameter over a long period of time. Climate change adaptation through traditional climate resilient livelihood is as basic as culture that controlled and utilized profitably for maintenance of social and environmental order (Jetu, 2012). Africa are suffering the worst climatic effects from the world's externality to the impacts of climate change. Climate change is extraordinary extended intensity of droughts and floods in Africa that altering climatic patterns and its extremes events adversely affecting African ability to grow and develop, political stability and social security. It also contributing to oceanic acidification and an increase in surface water temperatures around the African continent negatively affecting fish stocks and small-scale fishing communities (WISP, 2010; NMA, 2012 and Viste, et al., 2012).

In Africa impacts of extreme climatic events on economic sectors: food production and supply chain of agriculture, forestry and energy are severing food security (Desalegn et al., 2004). The Horn of Africa the recurrent livestock losses have plunged around eleven million people's livelihoods into crisis and triggered mass migration of pastoralists out of climate-affected areas (CIGI, 2010). The development of climate projections for Africa is evolving rapidly. Traditional African societies apply indigenous climatic forecast in administration of the impacts of extreme climatic events (Berisso, 2018). Ethiopian climatic impacts have been minimized by using traditional and improved early warning system. It is important that relief efforts and humanitarian responses should timely and well-coordinated during mitigation (Macharia and Kirema, 2016).

Territory and natural resources are the major sources of conflicts inducing extreme climatic events for which the violent and the peaceful category of conflict resolution mechanisms and community self-help can be a solution. The violent includes war and duel, whereas the peaceful includes avoidance, burying the conflict in the symbolic process, negotiation, mediation, arbitration and adjudication (Stark, 2011 and Abate, 2016). A number of studies have attributed conflicts to the huge scale competition for scarce resource. Alike government teams have established state institutions up to local level to represent households. In this regard, Oromo have indigenous institutions and livelihood practices for climate change adaptation (Huho and Ngaira, 2012). Such well respected institution among all Oromo society is known as Oromo Gadaa system. It has judicial committee 
who have the power to oversee the conflicts and impose decisions on it (Watson, 2001). The Oromo traditional administrative and justice system has operating within the institutional context of Gadaa system. The conflicts settlements and community self-help have been managed by Gadaa officials in line with the Oromo indigenous laws (Jetu, 2012). Even though the climate change resilience of community livelihood in study area has not been studied yet, these traditional practices are still functioning with inevitable changes. So, this study examines the climate change resilience of traditional community livelihood practices in Gadaa system.

\subsection{Statement of the problem}

Ethiopian extreme climatic events can be expressed in terms of the temporal and spatial variability of the hotness and precipitation (Desalegn et al., 2004 and Mekonnen, et al., 2017). Searching for water and grazing in dry season with little concern for wise use can results in competition and conflicts (Berhanu and Beyene, 2015). Such conflicts are also reducing the adaptive capacity of farmers and releasing greenhouse gases to extreme climatic events. Agricultural areas of study area has climatic problems whose impacts can be minimized by using traditional and modern early warning system, conflict settlement and community self-help livelihood. Historical alleviation techniques of extreme climatic events in the major parts of Oromia were not well investigated yet. In addition, indigenous climate resilience livelihood in the Oromo Gadaa system in general and that of study area in particular are relatively less studied. Thus, this study was attempted to bridge these missing gaps through investigating the climate resilient indigenous livelihood practices in Gadaa system.

\subsection{Objectives of the study}

\subsubsection{General objectives}

The general objective of this study was to investigate the climate resilient indigenous livelihood practices of Sikkoo-Mandoo's Gadaa system in selected zones of Oromia regional state.

\subsubsection{Specific objectives}

- To determine the early warning system to the climatic extreme used by farmers in study area.

- To identify and describe the conflict prevention and resolution mechanism in Gadaa system.

- To investigate the climate resilient community self-help livelihood practices in Gadaa system

\subsection{Research questions}

- What were those early warning system used by the majority of farmers in study area?

- What were those existing conflict prevention and resolution mechanism in Gadaa system?

- What were those climate resilient community self-help livelihood practices in Gadaa system?

\section{MATERIALS AND METHODS}

\subsection{Description of the study area}

The survey of indigenous early warning to extreme climatic events, conflict settlement and community self-help in Oromo gadaa system were conducted in selected districts of Arsi, East Shoa and West Arsi administrative zones of Oromia regional state. Elevation, annual temperature and rainfall of study area ranges from 1600 to $1900 \mathrm{~m}$ a.s.1., 18 to $27^{\circ} \mathrm{C}$ and 600 to $2400 \mathrm{~mm}$ respectively. It has sandy, silt and clay soil types (NMA, 2012). The land use and land cover of study area is mainly cultivated, settlement, pasture, forest, and mountainous (MOA, 2008). It is geographically located in between latitude of $5^{\circ} 48^{\prime} 5^{\prime \prime}$ to $9^{\circ} 8^{\prime} 20^{\prime \prime} \mathrm{N}$ and longitudes of $37^{\circ} 24^{\prime} 20^{\prime}$ to $40^{\circ} 44^{\prime} 20^{\prime} \mathrm{E}$ in Ethiopia. According to CSA, (2012) the householders in study area live on subsistence rain feed agriculture: animal raring and crop production. The main crop grown are wheat, burley, teff, maize, sorghum, vegetables and fruits whereas those of livestock are cattle, sheep, goat, horse, mule and donkey. 


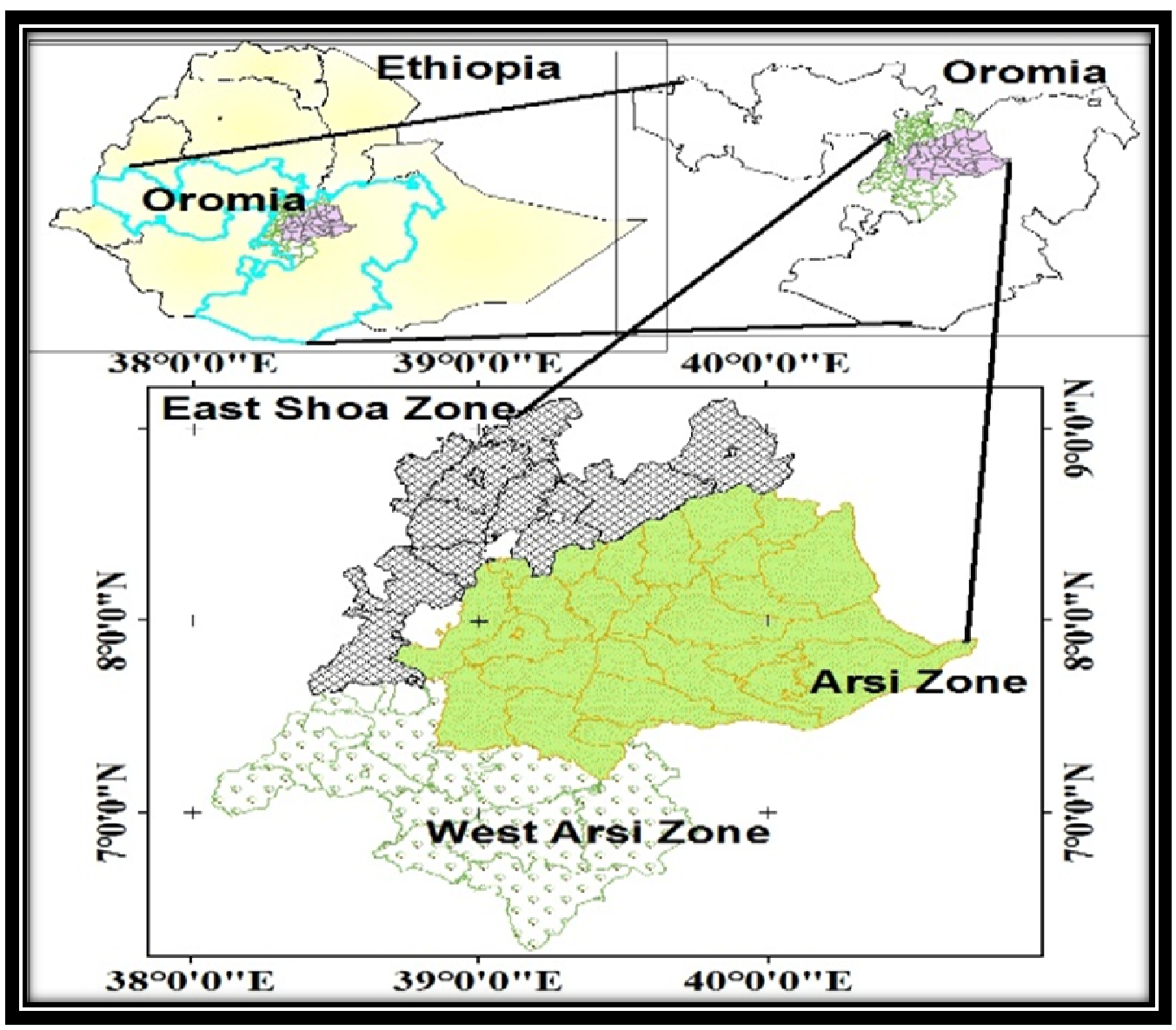

Figure 1: Geographical map of study area

\subsection{Sampling techniques}

\subsubsection{Site selection:}

The area, where the Sikkoo-Mandoo's Gadaa System and cultural norms are practiced, were taken into consideration during site selection. Hence, three zones: Arsi, East Shoa and West Arsi zones where were purposively selected from thematic area of Arsi University. Gadaa system is indigenous leadership which has preserved the culture of the Oromo. Selection of research site was focused to area where the institution of Gadaa system found and availability of data source for the intended research. The Diksis, Tiyo and Ziway Dugda districts from Arsi zone; Adami Tulu Jido Kombolcha and Adama districts from East Shoa zone and Aje and Kofale districts from West Arsi zone where Abbaa Gadaa, who is the chief leader in gadaa system, live were purposively selected. Hence, the same criteria and procedures was used to select sample kebeles, or the lowest administration level in Ethiopia, from the districts. To select sample kebeles, consultation with culture and tourism office at districts level were also made to identify the kebeles' where chief leader in Gadaa system live.

\subsubsection{Determination of sample size}

To determine the sample size, the researcher was used the following formula. As for key informants' selection, the researcher was included nine experts of culture and tourism at zone level and fourteen leaders of Gadaa system as a sample since their number is manageable. The homogenous nature of the householders have made the researcher to estimate sample of respondents at 5\% margin of error by using the following equation (Zar, 2010).

$n=K I+\frac{N}{1+N e^{2}}$.

Whereas;-

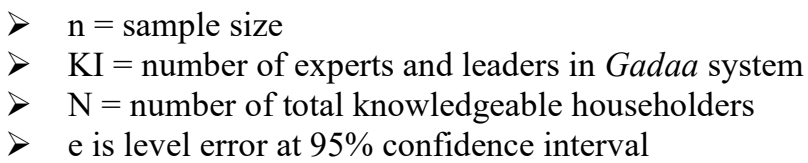




\subsubsection{Techniques and procedures of respondents selection}

The respondents were who lived in the area for long time and thus have knowledge of the area, culture, history and environment. The experts in government organization, leaders in Gadaa system and knowledgeable householders were selected and used as sources of data. First of all discussion with responsible government office were conducted to identify the experts working on related position and/or knowledgeable on Oromo Gadaa system for the study. Accordingly, total of nine experts in government organization: three experts from each of three zones were purposively selected as respondents. After that discussion with experts were done to identify the Abbaa Gadaa (chief leader) and Abbaa Sa'aa (leader of economic pillar) in Oromo Gadaa system. Hence total of fourteen leaders of Gadaa system: one Abbaa Gadaa and one Abbaa Sa'aa from each of seven districts were purposively selected. They were then used as a bridge through which the research reached at the intended community members and householders. Finally, householder selection followed two steps sampling procedures: the first step was conducting discussion with leaders of Gadaa system, total of 63 knowledgeable householders were identified from study area and listed as source of data. Then from the list, 54 householders were randomly selected while only 46 were availed and interviewed. The householders in study area have similar culture and norms of Gadaa system. As a result, it was unnecessary to look for more samples from study area.

\subsection{Methods of data collection}

Primary data was gathered from sampled respondents by employing 69 respondents' interview. The questionnaire were designed to address data on socio economic characters, local readership, and role of local leadership in climate change resilience. To accomplish this, sorts of checklist and/or guiding questions were used. Secondary data was gathered from all relevant sources such as government office, internet and webs/blogs. They was obtained through the review of different published and unpublished literatures \& documents like reports, researches, magazines, journal articles and books.

\subsection{Methods of data analysis}

In analysis the study was utilized Microsoft excel and Statistical Package for Social Science' (SPSS) software version 22 for the generation of result outputs. Collected data was analyzed by qualitative and quantitative data analysis techniques. To analyze the quantitative data the study was apply descriptive statistical tools such as measures of centrality (e.g. mean values and variances). Qualitative data was analyzed after the interpretation of listening, transcription and organization of the opining from the respondents. Finally, the results was summarized and expressed by using figure and table.

\section{RESULT AND DISCUSSION}

\subsection{Early warning to the extreme climatic events}

The prediction and early warning of extreme climatic events can alerts community to ensure their adaptive capacity in controlling the adverse impacts of the extreme events. Oromo have indigenous astronomical calendar, climatological, geological, trees' physiological and other entity's metaphysical views which reasonably linked to the environmental events they perceived. According to respondents the traditional early warning system has been moderated the impacts of adverse climatic events on communities' livelihood via climatological proxy, detection and prediction. The major source of early warning information (EWI) used by highest number of farmers were traditional indigenous early warning information disseminated from Raagaa Wogii (the spiritual leaders in Gadaa system) than modern early warning system disseminated by medias. Because within the community there is an emerging effort to find more accessible, suitable and easily understandable climate projections for their decision to use. Few farmers were not follow any early warning information to reduce the adverse impacts of climate change. The finding was also articulated associated indicators remarked as evidences. Raagaa Wogii are a spiritual leaders in gadaa system who mainly predicts climate variability from the ring of trees stem, thickness of deposited sediments, and direction of cloud and wind movement in each season. The future drought have been predicted from the frequency of past drought that can be obtained from the thickness of developed trees' stem ring and deposited runoff sediments in a year. The developed trees' stem ring and deposited runoff sediments in one year have similar color. The number of thin tree's rings and/or deposited sediments from 40 of them in total shows the number of drought in five Gadaa period (four decades). In this regard, out of 40 observed tree's rings and/or deposited sediments eleven are relatively thin means eleven drought were occurred in five Gadaa period/40 years. Supporting this finding Berisso, (2018) showed that since 1985 famine, the Ethiopian government was strengthened infrastructural and logistical assessment capacity and early warning to ensure food security in pastoral and agricultural areas. Negassa (2013) also reported that the traditional forecasters named Ayyantu recently being followed by development practitioners in their climate change impacts controlling efforts while councils of elders represent the needs and interests of the community. Similar indigenous knowledge of early warning to extreme climatic events in this finding was also reported by Abate (2016) from southern parties 
of Ethiopia.

Table 1: Source of early warning information to communities in Gadaa system

\begin{tabular}{|l|l|l|l|l|l|l|l|}
\hline No & Sources of EWI & N & Mean & SE & SD & $\begin{array}{l}\text { Min. } \\
\text { value }\end{array}$ & $\begin{array}{l}\text { Max. } \\
\text { value }\end{array}$ \\
\hline 1 & Raagaa Wogii (spiritual leader) & 69 & 4.1039 & 0.03500 & 0.30713 & 4.00 & 5.00 \\
\hline 2 & Medias like: TV, Radio and etc & 69 & 4.0649 & 0.21427 & 1.88021 & 0.00 & 5.00 \\
\hline 3 & DA (experts at local gov't office) & 69 & 3.2597 & 0.07255 & 0.63666 & 3.00 & 5.00 \\
\hline 4 & 69 & 2.1039 & 0.06292 & 0.55213 & 0.00 & 4.00 \\
\hline
\end{tabular}

\subsection{Conflict settlement mechanisms in Oromo Gadaa system}

Conflicts are most influencing factors that accelerates human vulnerability to extreme climatic events mainly by reducing their adaptive capacity and releasing greenhouse gases to atmosphere. Such effects can thus reversed by the indigenous mechanism of conflict prevention and resolution. Oromo Gadaa system is the indigenous knowledge, belief, culture, leadership and institution used in inter- and intra-ethnic conflict prevention and resolution even though it was threatened under the influence of Amhara ruling elites for around 1.5 centuries. It was deliberately detested and distorted as backward views and bad practices to devastate Oromo's identity and intellectual leadership. This study was investigated the existing indigenous knowledge of Oromo in conflict prevention and resolution. Safuu is a moral norms and values that deals with respect good will and forbid wrong customs to maintain mutual relationship of societies within intra and extra-terrestrial. Whereas Seera is the fundamental rules and regulations in Oromo Gadaa system. Safuu Seeraa is laws, moral and ethical norms in Oromo Gadaa system that protects the economic, environmental, sociocultural and political rights of human being as humanity irrespective of his/her ethnic groups. As indicated by the respondents, elders at different level responsible to reconcile the parties in conflict. When it is too difficult for elders to settle the conflict they call for the involvement of leaders at different level in Gadaa system such as: Hayyuus, Ambaa gadaa, Haadha siiqee, Abbaa Gadaas and/or spiritual leaders. The Jaarsummaa is dealing with conflict within Oromo and/or other ethnic group living and/or having a case with Oromo. The Sadii walii dhoksuu, Sadii walii obsuu, Sadii walgorsuu and Araaramuи are conflicts prevention mechanisms settled by two parties without anyone interference. Ilmo-limmoo is the responsibility of relatively unharmed person or groups to help the harmed one in any costs to control the effects without waiting for order from leaders. Araarsuu and Qora are also other indigenous mechanism of conflict resolution conducted by either two groups of hayyuu ollaa or Ambaa Gadaa by dealing and solving the cases and related causes from a base. Gumaa is a duty of Abbaa gadaas and Spritual leaders to help hayyuus and Ambaa Gadaa at different level in hearing the cases and its causes from two parties and their Ollas in detail and make decision based on the level of crime.

Worra Gumaa is Families between whom there are blood feuds caused by killing of.

Seera siinqeef qanafaa is also commonly used by women to protect their rights and to participate in every issues in their environment. Although, the laws in Gadaa system are in the form of unwritten constitution, its rules and regulations have been transferred from generation to generation through oral and practices. For instance, people full rights to guula, means their political rights to resign from his political party (gogeessa) and join another gogeessa by using the principles of Gadaa System have been transferred from generation to generation both through oral and practices. Some of this indigenous mechanism of conflict resolution of Sikkoo-Mandoo (Arsi) societies in Bale zone of Oromia region were also reported by Birhan and Bekele (2016). In line to this finding many other traditional mechanism of conflict settlement of Oromo were reported by many others scholars: ilaafilaamee/negotiation (Abebe, 2001 and Zelalem and Endalcachew, 2014); jaarsa araara system means reconciliation through elders and Jaarsummaa system/mediation (Amenu, 2018); Gumaa is blood price to settle homicide, (Gemechu, 2002 and Gowok, 2008), Qalluu courts is court of spirit possessed person named Qalluu who assists the conflicts to negotiate, or through arbitration (Lewis, 1984b and Morton, 1975), women use law of seera siiqqeef Caаccuu to protect their right through their representatives called shanee even without witnesses testifying to the case (Bartels, 1984). The Oromo's mechanism of conflict prevention and resolution were also reported by many other researchers (Watson, 2001 and Dejene. 2013). Similar to that of Oromo Gadaa system, indigenous conflict settlement: in Wolayta is Gondaro (Berhane, 1992), and in Sidama is ostracization (Hamer, 1972), and in Gurage is Yagoka (Shack, 1969). Likewise, Evans-Pritchard (1940) documented that the leopard skin chief have a power of mediating the conflicts in the Nuer of the Sudan. Bawku in Ghana (Bukari, 2013) and Meta in Western Cameroon were also executing their fellow villagers, kinsmen and friends for their wrong doings. A troublesome member of a community is denied clan protection, and is thus isolated from societies. 
Table 2; Mechanism of conflict induced extreme climatic effect management

\begin{tabular}{|l|l|l|}
\hline Terminology & Relative meaning & \multicolumn{1}{|c|}{$\begin{array}{c}\text { Actors: Responsible } \\
\text { person }\end{array}$} \\
\hline Safuuf Seera & Laws, moral and ethical norms in Gadaa system & Abbaa Gadaas \\
\hline Jaarsummaa & Dealing with conflict & Individual to leader \\
\hline Sadii walii dhoksuu & $\begin{array}{l}\text { Secretiveness for three time is mostly used to prevent } \\
\text { conflict in family (Mattii) to neighbors (Ollaa) }\end{array}$ & Two parties \\
\hline Sadii walii obsuu & $\begin{array}{l}\text { Threeness tolerance to prevent conflict in family, peasant } \\
\text { associations (Arada/Dheeda) to district (Eelaas/Maddaa) }\end{array}$ & Two parties \\
\hline Sadii walgorsuu & $\begin{array}{l}\text { One another counsel for three time is mostly used to } \\
\text { prevent conflict in family to gosa (Clan) }\end{array}$ & Two parties \\
\hline Araaramuu & Negotiation is mostly used to prevent conflict & - Two parties \\
\hline Ilmo-limmoo & Helping harmed person in any case & Criminal \\
\hline Araarsuu & Mediation is mostly used to solve conflict at all & Hayyuu ollaa \\
\hline Qora & Arbitration is mostly used to solve conflict at all & Ambaa Gadaa \\
\hline Daadhii buudaa & Mediation is mostly used to solve conflict at all & Ambaa Gadaa \\
\hline Gumaa & Reimbursement & Abbaa gadaa \\
\hline Wonteef woraana & Defends env'tal resources from destroy. & Haadha siiqee (women) \\
\hline Siinqeef Qanafaa & $\begin{array}{l}\text { The power of womens in Gadaa system, institutionalized } \\
\text { and women formed parallel organizations of their own } \\
\text { which actively excluded men. }\end{array}$ & \\
\hline
\end{tabular}

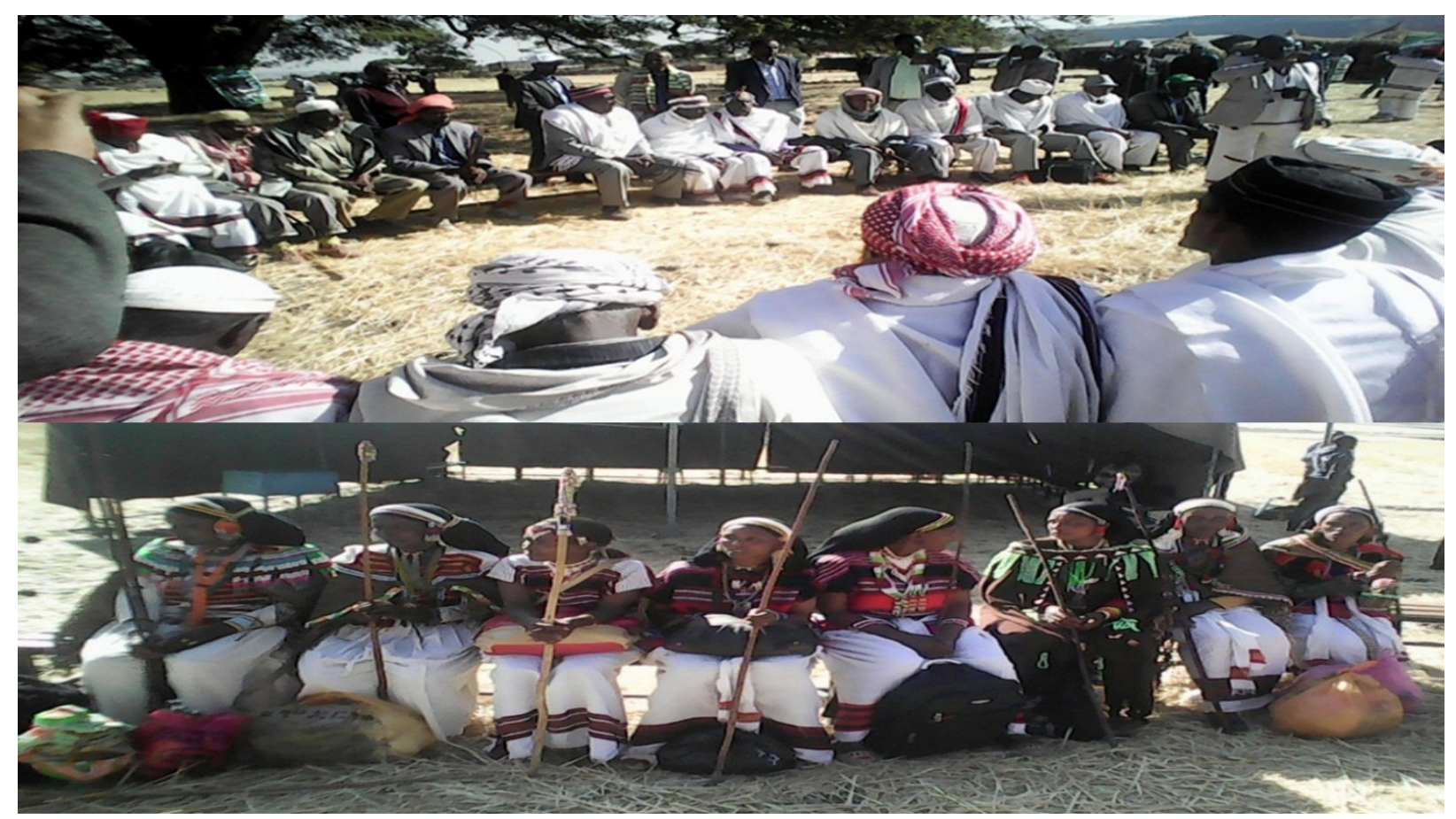

Figure 2: When Abbaa Gadaas and Haadha Siinqee are settling the conflicts

\subsection{Climate resilient community self-help livelihood practices in gadaa system}

Climate resilient livelihoods are the climate change adaptation strategies used to control the adverse impacts of extreme climatic events by exploiting beneficial opportunities. The adaptation strategies to extreme climatic events used in study area were recorded in all types of farmers' livelihoods. Community self-helps is one of the livelihood mechanism in Gadaa system that has been used to solve livelihood problems of Oromo society. As climate resilient livelihoods, the respondents were listed total of sixteen community self-help practices those have been experienced in Sikkoo-Mandoo Oromo societies. These sixteen practices of community self-help livelihood were then classified into six groups based on their actor named: those managed by Ambaa Gadaa who is the chief leader in gosa (clans), by members of their clan, both by friends and family, by family, by friend and by neighbors. Majorities of community self-helps are the responsibilities of members in their clan, and friends/families (table-3). Ameesa dabarsu is the ways in which communities helping one another through lactating caw transfer to the one who have no lactating caw. The farmer who have many lactating caws transfers 
one to the poor farmer in their clan to let him use milk and its products. Dabaree kenuu is the ways in which rich farmer in the same clan helps poor farmers through caw transfer to share its calves. The poor farmer receive $1 / 3$ of caw's calve whereas $2 / 3$ of calves and mother caw would returned back and owned by rich farmer. Gegawogegesaa is the duties of female's clan in donation of house material, land and/or livestock for pair at the date of their marriage. Dhoofsisuu is the responsibilities of men's families in donation of land and/or livestock for pair within a week of their marriage. Horii soruu is the ways in which rich people freely give livestock to the poor farmers in their clan. It is also freely restocking livestock of person/groups in their clan whose livestock were treated by drought, flooding or any other disasters. Hirphuu is the ways in which grain for food and/or livestock for raring are given to pro-poor from members of his clan. Dikee hirphuu is the ways in which friends/families helps one another by sharing animal waste for use. Gumaata is the technique in which friends and/or families supports injured person/groups mainly by donating cultural food until they repaired from hurt. Liqii is the ways in which friends/families helps one another by providing credit for the one in problem. Qabdoo qabuuf is constructing house for the person in problem such as elder, women, disable and militaries. Qote-qotii is the technique in which rich farmers who have many oxen but not human labor for agricultural practice and the poor one who have no ox helps one another in ploughing. The poor farmers uses to plough his and the rich farmer farmlands by using rich farmer oxen. Thus they solves one another problems by collaborating oxen and human labor in farming. Sanyii kennuu is the ways in which friends/families helps one another through germplasm exchange. Woliif Tiksuu is the ways in which friends/families helps each other by flocking livestock for one another. Daboo is helping one another by working in group mainly during agricultural practices, housing and fencing. Edir and/or Ekub is a saving group in which members can get credits from the association for adaptation purposes whenever crop production failed by extreme climatic events. Inline to this finding Jalata (2012) was illustrated how Oromo gadaa system organized Oromo society around socio-political, economic, cultural and religious institutions by preventing disasters and promoting relative peace, security, sustainable development, and political sovereignty. In consistence of this finding the role Ethiopian mutual support systems in climate change adaptation was also reported by (WISP, 2010; Boru, 2012; Nigatu, 2013; and Getahun, 2016). Likewise, the role of indigenous knowledge in climate change adaptation strategy in different parties of Ethiopia was also elaborated by Dejene (2013) and Abate (2016). Alike Abbaa Gadaas in our case, Huho and Ngaira, (2012) and John, et al., (2018) also proposed the involvement of the highly experienced, knowledgeable and skilled persons in proper management of valuable land resource while used for common good as part of risk management.

Table 3: Indigenous community self-help livelihood used in adaptation to extreme climatic event

\begin{tabular}{|c|c|c|}
\hline Adaptation strategies & $\begin{array}{c}\text { Relative meaning of inborn terminology in Oromo Gadaa } \\
\text { system }\end{array}$ & $\begin{array}{l}\text { Actors: Responsible } \\
\text { person }\end{array}$ \\
\hline Ameesa dabarsu & Lactating caw transfer for milk and its product aid & Members of their clan \\
\hline Dabaree kenuи & Livestock transfer to share $1 / 3$ of its Calves & Members of their clan \\
\hline Gegawo gegesaan & Livestock gift during wedding by female family & Members of their clan \\
\hline Horii soruu & Restocking & Members of their clan \\
\hline Hirphuu & Crop/Livestock donation for pro-poor & Ambaa Gadaa or clan \\
\hline Dikee hirphuu & Sharing animal waste for use & Friends/ Family \\
\hline Gumaata & Reparation or Compensation when injured & Friends/ Family \\
\hline Liqii & Credit for person in problem & Friends/ Family \\
\hline Qabdoo qabuuf & Housing the person in problem & Friends/ Family \\
\hline Qote qotii & Exchanging Ox labor by his lobor in farming & Friends/ Family \\
\hline Sanyii kennuu & Seed or Germplasm exchange to be sown & Friends/ Family \\
\hline Woliif Tiksuu & Flocking livestock for others & Friends/ Family \\
\hline Dhoofsisuu & Land/Livestock donation for marriage by male family & Family \\
\hline Daboo & Helping others by lobour & Friends \\
\hline Edir and Ekub & Traditional Saving group & Neighbors \\
\hline
\end{tabular}

\section{CONCLUSION AND RECOMMENDATIONS}

The Oromo have indigenous knowledge on the management of environmental disasters and risk through climate resilient livelihood practices. The indigenous climate resilient livelihood practices in study area include: early warning, conflict settlement, and community self-help practices. Majority of farmers have been used indigenous early warning information predicted by spiritual leaders than that of modern prediction disseminated by Medias. Because of relatively inaccessibility, complexity and difficulties of the science of modern climatic projection for 
farmers to use. Raagaa Wogii are spritaul leaders in gadaa system predicting extreme climatic events from the ring of trees, thickness of deposited sediment layer, and direction of wind movement. An eleven thin per 40 tree's rings and/or deposited sediments means eleven drought were occurred in five Gadaa period/40 years.

Conflicts are accelerating human vulnerability to extreme climatic events by releasing greenhouse gases to atmosphere. Its effects can however alleviated by the community based conflict settlement. Oromo Gadaa system have indigenous knowledge, institutions and role players on conflict prevention and resolution as indicated by orally transferred unwritten law, moral and ethical norms called Safuuf Seera. Jaarsummaa is used to settle the conflict among Oromo and others ethnic group having a case with them. Sadii walii dhoksuu, Sadii walii obsuu, Sadii walgorsuu and Araaramuu, are conflicts prevention mechanisms enforced by two parties without anyone order. Ilmo-limmoo is the responsibility of unharmed party to help the harmed party in cost of controlling the effects whereas Araarsuu and Qora are duties of hayyuu to deal related causes from a base and solve the cases. Gumaa is solved by Abbaa gadaas, Ambaa Gadaa and hayyuus at different level by hearing the cases and its causes from two parties and their Ollas in detail to make decision. Seera siinqee is duties of women to protect their rights and to take party in every issues in their communities.

The sixteen practices of climate resilient community self-help livelihood have been managed at six community level namely by: leaders in Gadaa system, members of their clan, friends/family, family, friend and neighbors. The Ameesa dabarsu, Dabaree kenuu, Gegawo-gegesaa, Soruu and Hirphuu were the indigenous community self-help livelihood enforced by members of their clan. Dikee hirphuu, Gumaata, Liqii, Qabdoo qabuuf, Qote-qotii, Sanyii kennuu and Woliif Tiksuu were the ways in which friends/families helps each other during extreme climatic event. Dhoofsisuu, Daboo, and Edir and/or Ekub have been the responsibilities of men's families, friends and neighbors respectively to help one another. Therefore this indigenous early warning system, conflict prevention and resolution, and community self-help livelihood practices ought to scaled up to legal level and used at a regional level in order to mitigate extreme climatic events. Further study and modernization of the evidences, reliability and effectiveness of the indigenous early warning system are also very important.

\section{ACKNOWLEDGEMENTS}

The Authors are very grateful to Culture and Tourism office in Arsi, East Shoa and West Arsi zones for their cooperation. We would also like to thank respondents for their valuable data provision in data collection. Arsi University is appreciated for its financial support to this research project.

\section{REFERENCES}

Asafa Jalata, 2012. Gadaa (Oromo Democracy): An Example of Classical African Civilization. Department of Sociology Knoxville, University of Tennessee, Knoxville.

Asefa Abebe, 2001. Indigenous Mechanisms for the Prevention and Resolution of Conflict: The Experience of Oromo in Ethiopia". Paper presented to the Workshop on Conflict in the Horn: Prevention and Resolution organized by the Ethiopia Chapter of OSSREA, May 11-12, 2001. Addis Ababa, Ethiopia.

Bartels, Lambert (1984). Oromo Religion: Myths and Rites of the Western Oromo of Ethiopia. An Attempt to Understand. Berlin: Dietrich Reimer Verlag.

Bukari, K., 2013. Exploring indigenous approaches to conflict resolution: The Case of Bawku in Ghana; Accra: Center for Development Research, University of Bonn.

CIGI, 2010. Climate Change in Africa: Adaptation, Mitigation and Governance Challenges. CIGI Special Report.

CSA, 2012. Welfare monitoring Survey, Summary Report. Federal Democratic Republic of Ethiopia (FDRE), Central Statistical Agency (CSA), Addis Ababa, Ethiopia.

Dejene Gemechu, 2002. Some aspects of conflict and conflict resolution among Waliso Oromo of Eastern Macha, with particular emphasis on the Guma. Addis Ababa University, Ethiopia.

Dejene Negassa, 2013. Local Institutions, External Interventions, and Adaptation to Climate Change: The case of the Borana pastoralists in southern Ethiopia. Research Backgrounder series, Oxfam America.

Desalegn Ch.,Babel M., DasGupta A., Seleshi B. and Merret D. 2004. Farmer perception about water management under drought condition in Awash river basin, Ethiopia. International Journal of water resource development. $14 \mathrm{PP}$.

Endalkachew Birhan and Girma Bekele, 2016. Challenges and Opportunities of Indigenous Conflict Resolution Mechanism in Oromia Regional State: The Case of Rayitu Woreda, Bale Zone, Oromia, Ethiopia.

Evans-Pritchard, E., 1940. The Nuer: A Description of the Mode of Livelihood and Political Institutions of Nilotic People. New York: Oxford University Press.

Geremew Nigatu, 2013. Gadaa theory and practices: political process and system of conflict resolution in Gadaa institution.. Oslo, Norway.

Gowok, S., 2008. Alternative dispute resolution in Ethiopia: A legal framework of African research review 8(1) 66-79.

Halake Boru, 2012. Pastoral livelihood diversification and food security: The case of Yabalo woreda, Oromia 
National Regional State. Masther's thesis. Ethiopian Civil Service University, Addis Ababa, Ethiopia.

Hamer J., 1972. Conflict Settlement and Sanctity. An Ethiopian Example". In An Anthropological Quarterly, Vol 45.No. 4, pp 232-247. Washington, D.C: The Catholic University of America Press.

Huho, J. and Ngaira, J., 2012. Pastoralism and the changing climate in the arid northern Kenya; In livestock: rearing, farming practices and diseases.

Jetu, E., 2012. Mediating criminal matters in Ethiopian criminal justice system: The prospect of restorative justice system, Oromia law journal 4(3) 102-112.

John, L., Were, E., \& Kandagor, D., 2018. The Role of Indigenous Conflict Resolution Mechanism Actors on Land Use Management in Pokot Central Sub-County. International Journal of Academic Research in Business and Social Sciences, 8(4), 180-193.

Lewis Herbert, 1964b. A Galla Monarchy: Jimma Abba Jifar, Ethiopia 1830 - 1932. Madison and Milwaukee: The University of Wisconsin Press.

Macharia and Kirema, 2016. Resolving conflicts using indigenous institutions: A case study of Njuri-Ncheke of Ameru, International Journal of Science Arts and Commerce 1(1) 33-46.

Melaku Getahun, 2016. Oromo Indigenous Knowledge and Practices in Natural Resources Management: Land, Forest, and Water in Focus. J Ecosys Ecograph 6: 181

Miressa Amenu, 2018. Exploring the current practices of Jaarsumma as indigenous conflict resolution mechanisms: The case of Dambi Dollo Town, Oromia, Ethiopia.

MOA, 2008. Relief interventions in pastoralist areas of Ethiopia. Minster of Agriculture and Rural Development. Addis Ababa, Ethiopia. 48p.

Morton, A., 1975. "Mystical Advocates: Explanation and Spirit Sanctioned Adjudication in the Shoa Galla Ayana Cult". In Proceedings of the First United States Conference on Ethiopian Studies: Michigan State University: African Studies Center. Pp 73-89..

NMA, 2012. Twenty seven years meteorological data's (Temperature and rainfall data) for Yabello Station in South Ethiopia. National Meteorological Agency.

Shack William, 1966. The Gurage: A People of the Ensete Culture. London: Oxford University Press.

Stark, J., 2011. Climate Change and Conflict in Pastoralist Regions of Ethiopia: Mounting Challenges, Emerging Responses. USAID (U.S. Agency for International Development). www.usaid.gov.

Taddesse Berisso, 2018. The Oromoo Gadaa System: Why Considered Democratic?.Gadaa Journal/ Barruulee Gadaa. A Bilingual Journal of Institute of Oromoo Studies (IOS), Jimma University. ISSN: 2616-3977. Vol.1 No.1. 130pp. https:www.ju.edu.et/gj

Tesfaye Dejene. 2013. The Role of Indigenous Knowledge in Climate Change Adaptation: The Case of Guji Pastoralists in DugdaDawa District, Borana Zone South Ethiopia. MS.c Thesis. Hawassa University Wondo Genet College of Forestry and Natural Resources Climate Change and development, Wondo Genet, Ethiopia. 141P.

Teshome Abate, 2016. Contribution of Indigenous Knowledge to Climate Change and Adaptation Response in Southern Ethiopia. Journal of Earth Science and Climate change 7: 377. DOI: 10.4172/2157-7617.1000377

Tsehay Berhane, 1992. "Gondaro: A Ritual of Conflict Resolution in Wolyata." In Sociology Ethnology Bulletin, vol.1, No.2. March 1992. Pp 65-66. Addis Ababa University.

Viste, E., Sorteberg, A., and Diriba Korecha, 2012. Recent drought and precipitation tendencies in Ethiopia. Springer-verlag, TheorApplClimatol (2013) 112:535-551 DOI 10.1007/s00704-012-0746-3.

Wassie Berhanu and Fekadu Beyene, 2015. Climate Variability and Household Adaptation Strategies in Southern Ethiopia. Journal of Sustainability, ISSN 2071-1050.

Watson E., 2001. Inter institutional alliances and conflicts in natural resources management: Preliminary research findings from Borana, Oromiya region, Ethiopia. Marena research project, working paper No. 4.

WISP, 2010. Building climate change resilience for African livestock in sub-Saharan Africa. World Initiative for Sustainable Pastoralism (WISP): a program of IUCN - The International Union for Conservation of Nature, Eastern and Southern Africa Regional Office, Nairobi. ISBN: 978-2-8317-1260-4.www.iucn.org/wisp.

Zar J. 2010. Biostatistical analysis: department of biological sciences. 3rd ed. New York (NY): Northern Illinois University.

Zelalem M. and Endalcachew, B., 2014. Traditional Conflict Resolution Mechanisms among Ambo Woreda Communities, International Journal of Research 8(1).

Zenebe Mekonnen. Teshale Woldeamanuel, Zebene Asfaw and Habtemariam Kassa, 2017. Analysis of observed and perceived climate change and variability in Arsi Negele District, Ethiopia. Environ Dev Sustain (2018) 20:1191-1212. 